\title{
SEPARACIÓN PARENTAL: HUELLAS MNÉMICAS DE LOS FENÓMENOS FÁCTICOS DISRUPTIVOS EN LOS DIBUJOS DE NIÑOS.
}

PARENTAL SEPARATION: MNEMIC TRACES OF DISRUPTIVE

FACTUAL PHENOMENAL IN CHILDREN'S DRAWINGS

Dilcio Dantas Guedes

Family Services Toronto, Canadá

Correspondencia:dilcio@gmail.com

\section{RESUMEN}

Este ensayo articula consideraciones teóricas sobre el uso de los recuerdos y los olvidos en la producción proyectiva gráfica de los niños latentes y la experiencia de la separación de sus padres. Los dibujos son comprendidos como materiales basados en huellas mnémicas que pueden evidenciar la reconstrucción de sus vivencias para sí mismos. Sin embargo, el examen de la bibliografía sugiere que, en muchos casos, la experiencia de la separación parental engendra en la psique de los niños un efecto desestabilizador asociadas a heridas narcisistas y a la formación de representaciones no elaboradas. El conjunto de teorías que se han acumulado en relación con el tema convergen hacia el postulado que el recuerdo y el olvido en las producciones proyectivas de los niños remitiría, mediante procesos de elaboración secundaria, a componentes asociativos que filtrarían sus contenidos latentes, facilitarían la simbolización de tramas conflictivas y la reelaboración de esos recuerdos. 
Palabras clave: Separación de los padres, Duelo, Recuerdos, Olvidos, Proyección.

\section{ABSTRACT}

This essay articulates theoretical considerations on the use of reminiscences and the forgetfulness in the projective graphic production of latent children and the experience of parental separation. In this review, drawings are understood as materials based on mnemonic traces that may evidence the reconstruction of their experiences for themselves. However, a review of the literature suggests that the experience of parental separation engenders, in many cases, a destabilising effect on children's psyches associated with narcissistic injuries and the formation of unelaborated representations. The set of theories accumulated in relation to the subject converge towards the postulate that reminiscences and the forgetfulness in children's projective productions would refer, through processes of secondary elaboration, to associative components that would filter their latent contents, facilitate the symbolisation of conflictive plots and the reelaboration of memories.

Key words: Parental Separation, Grief, Reminiscences, Forgetfulness, Projection.

\section{INTRODUCCIÓN}

Desde el comienzo de la práctica del análisis con los niños (Von Helmuth, 1919; Morgenstern, 1927, 1930, 1937, 1939; Freud, 1965, 1971; Klein, 1939), se consideraban los dibujos como un mediador de la comunicación del inconsciente. Se suponía que la interpretación de los dibujos (así como del jugar y de otros comportamientos aparentemente no intencionados) permitía acceder a significados inconscientes más profundos de los síntomas del niño, de su proceso de desarrollo y de los obstáculos que enfrenta hacia la autonomía. Los autores citados indicaron que estas manifestaciones eran 
comparables a los sueños. Freud (1900) ya había afirmado que los sueños son asociaciones de la vida objetiva y subjetiva de los individuos. Pero, ¿cuál es la relación entre estas producciones gráficas y la rememoración de las experiencias, especialmente las experiencias asociadas a los fenómenos disruptivos, como la separación parental?

Se parte de la tesis que a través de la investigación de los materiales proyectivos se podría alcanzar las dimensiones de la psiquisación de fenómenos no elaborados. Tales dimensiones remitirían a la construcción intersubjetiva del sujeto y de qué manera tramita la construcción social e individual de su memoria. Se cuestiona sobre la articulación entre los recuerdos, el olvido y los materiales proyectivos en dibujos de niños latentes.

Una cuestión clínica que se pone se relaciona a la utilización de los recuerdos para dar cuenta sus síntomas y perturbaciones, una vez que esta evocación pondría el sujeto consciente de la verdad de su inconsciente. En la misma perspectiva, ¿la interpretación de los materiales proyectivos gráficos sirve para alcanzar la evocación de los recuerdos a fin de lograr el mismo objetivo? Es en ese contexto, se propone articular elementos teóricos sobre la experiencia de la separación parental para los hijos, el duelo vivido y la producción de material gráfico que pueda representar la rememoración de esas experiencias.

Metodológicamente, este manuscrito se basa en cuanto una revisión teórica de la literatura, en la cual se ha centrado en un conjunto de teorías que se han acumulado en relación con el tema de los recuerdos y los olvidos, los materiales proyectivos en el periodo de latencia y la situación de separación parental. 


\section{MARCO TEÓRICO}

Para responder a estas preguntas, se utilizan referencias que remontan el camino en el que Freud desarrolló sus ideas sobre los recuerdos. En seguida, se presentan consideraciones sobre los temas del recuerdo y del olvido en la contemporaneidad para, asociarlos al tema de la actividad representacional del psiquismo, a un breve histórico sobre el análisis de los niños y al uso de dibujos. En continuación, articula al tema de la separación de los padres a la luz de los materiales gráficos producidos por niños latentes y su proceso de duelo.

\section{Freud y los recuerdos:}

No es absurdo considerar que cualquier discurso sobre el inconsciente presupone una discusión sobre la memoria. Eso es debido a que el inconsciente es un depositario en la memoria de las representaciones afectivas relacionadas con las experiencias, fantasías y defensas que el individuo posee desde el principio de su vida. Esto está en línea con lo que Freud propone que el recuerdo de las memorias de la infancia define uno de los pilares del método psicoanalítico. Sin embargo, Freud se cuestionaba si el material psíquico contenido en estos recuerdos se basaba en hechos o más bien en la ficción narrativa.

Desde el principio de los estudios sobre la histeria, Freud aplicaba métodos propios para dar cuenta de la realidad material, es decir, para buscar los hechos precisos de la vida del paciente. A pesar de ello, Freud propuso, basándose en el sesgo de su teoría de la seducción, que la cura de un paciente dependería de la recuperación mnémica de su historia porque, desde el punto de vista económico, tales experiencias probablemente generaban un exceso de excitación que se traducía en síntomas. 
Freud veía que sus pacientes histéricas presentaban un deseo de recordar que era contradictorio por ser, al mismo tiempo, un recuerdo penoso. De esta manera, los síntomas histéricos serían, al mismo tiempo, recuerdos reprimidos de su origen que simbolizaban un deseo de recordar $\mathrm{y}$, al mismo tiempo, de reprimir por temor en relación a los ideales morales. Los síntomas que sufrían serían, entonces, una forma de disociación que aplaza el resurgimiento, en la edad adulta, de los deseos asociados a esas experiencias para evitar sentimientos de vergüenza y culpa.

Freud nunca abandonó completamente la teoría de la seducción, si bien su abandono parcial permitió teorizar sobre las fantasías de seducción, nunca la abandonó del todo. Persistió cierta doble posibilidad. No obstante, descubrió que sus pacientes no reprimían los hechos reales, sino que tenían fantasías sexuales que eran tomadas como el equivalente simbólico de los deseos sexuales prohibidos y reprimidos. Así que, a partir de ese postulado, Freud definió que la técnica debería centrarse en la elaboración de estas fantasías.

A partir de la interpretación de los sueños, Freud (1900) entendió que la represión era un mecanismo que podía mantener el equilibrio psíquico de los pacientes. Eso implicaba que los sujetos tenían la capacidad de retener rastros de memoria ilimitados. Entonces, desde este enfoque, el objetivo del trabajo analítico sería reconstruir la historia del paciente para acceder al núcleo de su organización patógena y explicar los síntomas neuróticos.

Más tarde, Freud (1914) propuso que el análisis de la transferencia podría facilitar el acceso a recuerdos que no se manifestaban a través de los recuerdos per se sino a través de la acción. El análisis de la transferencia permitiría, en eses casos, descubrir superficies ocultas de la historia 
del paciente. Freud consideraba que ciertos prototipos, revelados por los elementos de un conflicto infantil, se presentaban a través de una compulsión de repetición (más a menudo asociada con una resistencia al recuerdo) - lo que obligó a Freud a poner en evidencia la existencia de una realidad psíquica compuesta de deseos inconscientes y fantasías asociadas.

En la carta 52 a Fliess, Freud (1896e) explicó su despliegue del proyecto del psicoanálisis, donde empieza a definir el mecanismo de represión, el preconsciente y el inconsciente, pero, sobre todo, su visión sobre la memoria. Para Freud, la memoria sería una especie de depósito donde todo está siendo grabado y almacenado. En la medida en que nos desarrollamos (fases de desarrollo psicosexual), los recuerdos de una fase anterior se están alterando, generando una distorsión de los recuerdos. Freud llamó a este proceso de construcción de la fantasía. Así, la memoria se concibiera desde una perspectiva de proceso dinámico y constructor de fantasías sobre las memorias del pasado. En ese momento, Freud comprendió que los únicos recuerdos que podían sufrir estas alteraciones eran los recuerdos sexuales. Otros recuerdos tendrían mantenerse como los originales, excepto si tenían carga desplacentera o traumática.

Para Freud, cuando la memoria sufre este tipo de alteración, significa que pasa por un proceso patológico. Por eso, explicó en esa carta que la memoria no debería pasar por estos cambios. Aunque pensaba que la memoria es dinámica, para él este dinamismo sería perjudicial. Así, postulaba su argumento sobre lo que justificaría el tratamiento analítico: funcionaría más como un método para eliminar (o disminuir al máximo) estos filtros alteradores (generalmente la represión y otros mecanismos de defensa) para lograr que el sujeto recuerde lo que realmente sucedió en su vida. 
Para Freud, según lo describe en la carta 52, en la clínica, un paciente siempre habla de una versión de los hechos, una vez que utiliza las huellas mnémicas establecidas más que el reordenamiento según nuevos nexos, se trata de una retrascripción. Para el psicoanálisis, esta narración sería siempre la narración de una memoria distorsionada. Por eso, técnicamente, se entendería que los actos y los discursos de los sujetos siempre indicarían un sentido contrario (que encubrirían los verdaderos motivos). Así, el analista se centraría en el olvido, los lapsus y los actos fallidos porque serían indicios de contenidos de los recuerdos de eventos originalmente vividos y las verdaderas intenciones del individuo. Si estos recuerdos habían sido negados a la conciencia, es porque estarían cargados de una energía dolorosa y despreciable y, por lo tanto, estarían en el centro del dolor del sujeto.

Luego introdujo perspectiva de la temporalidad a posteriori (nachtraglich). Por esa perspectiva, Freud sugirió que un síntoma neurótico no sería el resultado de un evento aislado sino de dos eventos o experiencias separadas. En algún momento, una experiencia precipitaría una revivificación interna que engendraría una segunda experiencia que activaría las huellas mnémicas dejadas por la primera experiencia. Más tarde, Freud propone que, en relación al tema de la memoria, estaba convencido de la existencia de un sistema constantemente reelaborado y transformado por sucesivas retranscripciones de su contenido según las diferentes circunstancias experienciadas a lo largo del tiempo.

En otras palabras, según Freud, no se trataría de que la experiencia vivida se remodelaría después, sino que, debido a una respuesta psíquica inadecuada, el sujeto no podría producir un significado, pero, sólo después, cuando dicha respuesta psíquica sea más adecuada según las nuevas experiencias vividas. 
En este contexto de desarrollo psíquico más maduro, se haría posible la formación de sucesivas transcripciones de la memoria. Esto indicaría que la experiencia en un determinado momento no se vive, a posteriori, de la misma manera, por razones de desarrollo y luego se convertiría en una evocación transformada. A partir de esto, Freud concluyó que la formación de los recuerdos se basa en dos posibles fuentes: de las huellas de la memoria factual de la infancia y de las fantasías de períodos posteriores. Así, al nivel clínico, concluyó que no se trataría tanto de la posibilidad de recuperar recuerdos precisos o antiguos, sino más bien de comprender cómo estos recuerdos vehicularían deseos y fantasías inconscientes subyacentes y reprimidos.

En cualquier caso, el tema del uso del recuerdo como recurso para dar cuenta del estado psicológico de un sujeto y promover su cura forma parte de un campo de cuestionamientos y de investigación. Freud (1908) se mantuvo en esta posición ambigua al considerar que sus recuerdos eran evocaciones de una construcción de la escena primitiva a partir de la percepción vivida o que eran una reconstrucción retrospectiva de sus fantasías - como bien fue evidenciado en su análisis del Hombre de los Lobos. En ese caso clínico, queda claro que el recuerdo puede funcionar como expresiones de una experiencia concreta o pueden servir de encubridores de algo más que se hace resistir.

Al final de su vida, Freud afirmó que estaba convencido de que el trabajo analítico tenía como objetivo reconstruir los acontecimientos, a partir del material psíquico proporcionado por el sujeto. Sin embargo, también consideró que el sujeto puede terminar construyendo un evento y llevarlo a la convicción de este evento y, después de eso, construir su recuerdo En su último Construcción del Análisis, Freud dice que no es posible hacer 
una reconstrucción global de los recuerdos originales ya que todos los individuos pasan por la castración y por lo tanto no pueden recordarlo todo (Freud, 1937).

\section{Consideraciones sobre el recuerdo y el olvido en la contemporaneidad:}

Desde el decenio de 1990, el problema del recuerdo y el olvido se ha convertido en un imperativo, especialmente en los casos de adultos que denunciaron su victimización del abuso infantil. Se pueden destacar tres corrientes de estudio en Psicología sobre esos temas: una que defiende la idea (muy cercana al Psicoanálisis) de que un evento como el abuso puede generar una interferencia en las capacidades de almacenamiento y recuperación de registros debido a procesos disociativos que funcionarían como mecanismos de defensa (Van der Kolk, 1995; Siegel, 1995). No obstante, la rememoración de estos acontecimientos sólo sería posible si el sujeto se encuentra en un estado o contexto comparable al del acontecimiento original.

Otra posición, conocida como la teoría del síndrome de la falsa memoria, sostiene que no sería posible recuperar los recuerdos de eventos pasados con tanta precisión y que, generalmente, lo que se producen son recuerdos influenciados por factores externos como opiniones y sugerencias (Loftus, 1993; Friedman, 1997). La tercera posición sostiene que es mucho más común preservar los rasgos mnémicos de las situaciones de crisis, desde el punto de vista emocional, porque las capacidades de almacenamiento, codificación y recuperación aumentan cuando se asocian a situaciones críticas, aspectos que podrían verificarse empíricamente (Koss, Tromp y Tharan, 1995). 
A pesar de los desacuerdos, los puntos comunes entre estos abordajes y el psicoanálisis son que la memoria no sería estática, sino transformadora; que el olvido sería el resultado de un proceso y tendría una función específica (como de defensa o de adaptación al contexto), que la memoria sería propensa a errores y distorsiones, pero que puede ser duradera y mejorada en determinadas circunstancias (como de crisis); y que la relación intersubjetiva (como la relación terapéutica) facilitaría la transformación del contenido recordado.

Muchos de estos aspectos parecen estar corroborados en la posición de Tesone (2002) quien explica que el proceso de rememoración implica que la memoria se organiza a través del sesgo intersubjetivo y que se constituye por dimensiones representativas (fantasmas). Así, una recreación del hecho recordado se modifica, al filo del tiempo, en relación con la red simbólica construida por el sujeto a partir de su organización libidinal, creando nuevas ligaduras psíquicas. Significa que el sujeto puede beneficiarse de olvidar memorias dichas desvitalizadas para producir una trama simbólica singular y reconstructiva.

Tal producción es reforzada por lo que Canteros (2007) describió sobre el recorrido realizado por el sujeto, cuya memoria se ubicaría como el espacio donde se constituiría su identidad, articulando el ser y el no-ser, el estar y el no-estar, lo sido y lo que se hubiera querido ser, el goce y el desplacentero - todas las ambivalencias e infinitas posibilidades de existencia en un constante un proceso de recursividad.

En vista de ese proceso de recursividad, Benyakar (2020) sugiere que, el sujeto, en su proceso vivencial, registra sus situaciones de vida y el modo en que las vivió, y tal registro, en cuanto fenómenos fácticos, provocan 
una alteración psíquica - una alteración que se daría porque el sujeto registra y asocia su percepción con el significado de la percepción, que, en sí, sugiere la articulación entre el afecto y la representación. Pare Benyakar (2020), la imposibilidad de tal articulación caracterizaría la disociación en lo traumático, que no es efecto de la represión. Desde esa perspectiva, diferencia tres modalidades de manifestación de la memoria: el recuerdo, la rememoración y la evocación repetitiva.

Según Benyakar (2020), el recuerdo sería el proceso donde la memoria de huellas mnémicas perceptuales y/o vivenciales articuladas pelo sujeto que se producen por una elaboración activa en dimensiones espacio-temporales definidas, por ejemplo, la asociación libre; algo en el presente que te haces recordar de algo en el pasado, etc. Ya la rememoración sería el proceso donde la memoria de huellas mnémicas y/o vivenciales estimuladas por algo que hacen emerger la experiencia de algo ya vivido (sensorial y/o vivencialmente). Uno ejemplo de ese proceso sería evitar pasar por un determinado lugar porque ese lugar me remite a algo que no me hace sentir bien. La evocación repetitiva sería un proceso donde la memoria emerge espontáneamente, incontrolable, de cualidad presente; el sujeto vive y revive lo fáctico. Sería lo equivalente al flashback. Se explica por la presencia de un incrustado, por no ser elaborado. La evocación repetitiva implica en una no metabolización y una fijación en el percepto. Como el percepto no puede ser pensado, genera un estado de sumisión al acaecido como si el sujeto viviese en un eterno presente (introducto) que, por su vez, generaría una herida narcisista a partir del cual el psiquismo intenta reparar por la vía de síntomas (transformaciones de intento reparador fallidos).

En ese contexto, la memoria de huellas mnémicas perceptuales y/o vivenciales también serían componentes de los registros asociativos de la 
experiencia que se proyectarían, en mayor o menor grado de filtraje, en los materiales proyectivos de acuerdo con el momento histórico del sujeto y su estructuración psíquica. ¿Y cómo se caracterizarían el periodo de latencia?

Freud postuló algunas ideas sobre el periodo que llamó, finalmente, de "latencia" en cuanto a los procesos de transición. Primero como un periodo de ausencia o relativa represión de la sexualidad; después, consideró como un almacenamiento de pulsiones sexuales y de ausencia de conflictos de orden sexual, que, más tarde, conceptualizó como una fase de amnesia de recuerdos sexuales tempranos. El término latencia surgió en los Tres Ensayos de 1905 para articular teóricamente el pasaje de la sexualidad infantil, la influencia de la cultura y la retomada de la sexualidad infantil durante el periodo de la adolescencia. Freud (1905) definió el término como un ahogo de las pulsiones sexuales, pero con posibles manifestaciones de actividades sexuales que son detenidas por la cultura a través del entorno educacional.

Más tarde, teorizó que tales procesos se emparan con el rechazo de las pulsiones sexuales a través de la formación reactiva, demostradas como vergüenza y asco. De esta forma, tales pulsiones serían sublimadas en aprendizaje y otras actividades artísticas, deportivas, juegos y sueños diurnos. En 1926, Freud concluyó que la latencia se configuraba por el sepultamiento del complejo de Edipo, la vigorización del superyó y la construcción de defensas de cuño ético y estético en el yo. De lo punto de vista del funcionamiento psíquico, Freud enfatizó que en este trabajo el niño busca contener sus impulsos masturbatorios y competir por la inversión de sus objetos de amor. 
Mientras presenta cierto nivel de autonomía y fluidez psicológica que le facilita operar desde el principio de la realidad, el niño se utiliza de la fantasía y del distanciamiento del entorno familiar para incrementar sus capacidades laborales e interpersonales con sus pares. Desde un punto de vista psicodinámico, su superyó se encuentra más permisivo y sus procesos identificatorios sufren una reorganización ante nuevas figuras interpersonales. Mismo que haya una operación de comportamientos asociados al recelo y el ocultamiento, hay también una búsqueda por otras figuras importantes como suporte capital.

Aunque sus defensas aplacan los impulsos agresivos y eróticos, el acercamiento a los objetos de amor es menos conflictiva y se focalizan sobre la exploración de interrelaciones personales por las cuales puede obtener y sostén de su auto-estima. Lo punto culminante de eses procesos remitiría al incremento de un "tramado identificatorio" y el pasaje del escoptofílico al epistemofílico. Se exige así un proceso de olvidar los aspectos de la realidad exterior que generan excitaciones endógenas intolerables para desplazarlas al afuera, como satisfacción de un deseo de controlar la realidad y transformarse a través de una personificación identificatoria con el espacio social - base para la actividad representacional del psiquismo.

\section{La actividad representacional del psiquismo:}

Según Sami-Ali (2004), Freud había asociado la idea de la proyección a la hipótesis del inconsciente y del aparato psíquico, explicando tal conexión en diferentes momentos. Por ejemplo, al principio, la asoció a la neurosis de angustia, como energía psíquica bloqueada debido a frustraciones sexuales que se acumula en la esfera somática - el psiquismo proyecta la excitación hacia el exterior (en el soma), se trata de un desplazamiento espacio temporal. Más tarde, la articuló a la teoría psicológica de las 
neurosis. Aquí, la proyección tiene función defensiva. Algo surge en la vida representativa que es intolerable (un sentimiento, representación o experiencia) que culmina en la represión de la representación, y desde ahí aparecen los síntomas. Las huellas mnémicas y los afectos asociados no pueden ser descritos, pero el Yo transforma la carga afectiva (en la histeria, por proceso de conversión; en la neurosis obsesiva, por desplazamiento; en la paranoia, por proyección).

Ya en su obra sobre los recuerdos encubridores, indicó que las proyecciones de fantasmas de impresiones precoces para realizar el deseo actual, donde el presente se disfraza en pasado. En ese punto, la dimensión temporal de la proyección es flagrante: lo ya visto se transforma en nunca visto. En 1905, sobre el tema de la Histeria, explicó que las acusaciones al otro son proyecciones de auto-reproches disfrazados. Así, la proyección se basaría en la percepción exacta de la realidad. Después, en 1911 sobre el caso Schreber: lo que se siente interiormente como amor, se percibe exteriormente como odio. Ahí, Freud diferenció la proyección normal de la patológica. La proyección normal es la localización de las percepciones en el espacio. La proyección patológica tiene rasgos reparadores pues intenta recrear una realidad negada o mantiene la relación del sujeto con la realidad (fantaseada).

Ya en 1913, en la obra Tótem y Tabú, explicó que el tabú implica en tendencias inconscientes opuestas (el deseo de actuar algo prohibido), pero las tendencias negativas (prohibidas) son proyectadas en el mundo externo. Las proyecciones serían sometidas a las percepciones, donde se focalizarían en lo que causa placer o displacer. Aquí la dimensión espacio es también flagrante. El espacio (adentro-afuera) se constituye como efecto de la cultura. Así, la proyección variaría de cultura a cultura. 
En 1915, al hablar del principio de placer y de lo inconsciente, Freud expresó que el yo introyecta lo que se asocia al placer y proyecta lo que asocia al displacer. Así la proyección tiene una función económica (regular los afectos y mantener la constancia - dimensión corporal), dinámica (desplazar hacia el exterior las excitaciones insoportables) y genética (articular la noción adentro-afuera, necesarias a la constitución yoica). Precisamente se asocia al fenómeno de la transferencia y la naturaleza del sueño, que es una externalización de un proceso interno con intento de dominar la realidad exterior, transformando los afectos dolorosos en percepciones del mundo exterior (función dinámica de origen filogenética) que de un punto de vista defensivo, puede presentarse como una busca de alivio (interno mental) al proyectar (sobre el otro) sus propios deseos - se apoya sobre el conocimiento del otro (otro = lo que quiero ignorar de mi) menos los aspectos intersubjetivos de la proyección.

No obstante, en su obra Inhibición, Síntoma y Angustia, Freud (1926) aseveró que la proyección en las fobias se asocia a desplazamientos, no es solo eso. Más tarde, Freud la asoció a la concepción religiosa del mundo al sugerir que la proyección moldea el mundo a fin de objetivar como cultural, personificarlo para identificarse. A partir de ese aporte, Freud sugirió que percibimos desde lo que somos y conocemos del otro. En ese sentido, las proyecciones están mediatizadas por "lo percepciones externas simétricas a los contenidos afectivos e ideativos que se proyectan" (SamiAli, 2004, p. 58) y, en cuanto fenómeno inconsciente, son traspasadas por las dimensiones vivenciales de orden espacial, temporal, corporal e intersubjetivo, que también son traspasados por la historia y la cultura.

En el periodo de latencia, el niño olvida sus fantasías edipianas para vivenciar otras experiencias intersubjetivas. Por eso sus proyecciones 
aluden, mediante procesos de elaboración secundaria, a componentes asociativos heterogéneos y disímiles pertenecientes al pasado y al presente que filtran sus contenidos latentes. Sus producciones proyectivas remitirían a una representación del espacio social decurrentes de una transformación de las cadenas asociativas desde sus huellas mnémicas y de sus representaciones de su cuerpo en tal espacio. Tal proceso necesitaría el olvido de sus vivencias para la construcción de nuevas representaciones de sí y del mundo - elementos que remiten a la construcción intersubjetiva del sujeto y en que tramitan la construcción social e individual de su memoria. De esa manera, al mismo tiempo que la condición de nuestra existencia modifica las representaciones de nuestros recuerdos, también va a modificar la actividad representacional de nuestro psiquismo. El análisis de niños y sus producciones proyectivas dan testimonio de cómo tal actividad se manifiesta.

\section{El análisis de los niños y el uso de dibujos:}

Los dibujos han sido instrumentos importantes en procesos analíticos de niños porque facilitan el análisis de la transferencia, de la represión de las ansiedades a través de las representaciones del desarrollo sexual y los fantasmas edípicos (Morgenstern, 1927, 1937, 1939), revelan la imagen inconsciente del cuerpo y liberan, a través de la transferencia, sus ansiedades neuróticas (Dolto, 1948, 1971, 1974 y 1981), la aparición de la condensación y el desplazamiento de los elementos inconscientes de la vida emocional (Sami-Ali, 2004), sus identificaciones y su autoexpresión en el entorno (Vinay, 2007), y permiten al niño realizar un proceso de libre asociación (Anzieu, 2008).

A modo de ilustración, Sophie Morgenstern(1927)-la primera psicoanalista de niños en Francia, describió el progreso terapéutico de una niña de nueve 
años que estaba internada en un hospital infantil. Esta niña presentaba un mutismo como síntoma principal. Sus dibujos se convirtieron en la única forma de comunicación posible. A partir de los dibujos, Morgenstern pudo investigar la transferencia y observar la descarga de sus ansiedades a través de las representaciones de su desarrollo sexual (diferencias de sexo, escena primitiva, curiosidad sobre la reproducción y la masturbación que interpretó como una curiosidad sexual obsesiva) y fantasías edípicas, que más tarde fueron confirmadas por la niña después de su cura. Este caso hizo a Morgenstern concluir que los dibujos facilitaron el acceso al inconsciente, disminuyeron sus ansiedades a través de la interpretación de sus derivados y habían conducido al paciente al uso progresivo de defensas más adaptables. En otro estudio, Morgenstern (1939) explicó cómo los dibujos podían simbolizar metáforas que denunciarían los conflictos y preocupaciones del niño o, en otras palabras, correlacionar este tipo de representación con los síntomas neuróticos. Observó que las neurosis específicas se evidencian mediante rasgos específicos en los dibujos, lo que reforzó su tesis sobre la forma en que permiten revelar ansiedades profundas que no sería posible expresar de otra manera.

Para Dolto, que fue entrenada por Morgenstern y se convirtió en su asistente en el Hospital Trousseau de París, los dibujos facilitaban la expresión de la dinámica de los impulsos del niño y sus preocupaciones más apremiantes, que podrían incluir la proyección de su Yo y las representaciones del ideal de Yo, sus relaciones con el mundo y su cuerpo dentro de este mundo. En su tesis explicita que el dibujo permite entrar en el núcleo de las representaciones imaginarias, pero aclara que también es una representación del Yo como una historia que se cuenta a sí mismo. 
Para Aberastury (1962), psicoanalista argentina de influencia kleiniana, el dibujo infantil, como el juego y el sueño, serían producciones que funcionarían como plataformas para la elaboración de situaciones que el ego experimentaría como excesivas. Estas producciones tendrían una función catártica y su repetición articularía una asimilación constante y progresiva de las experiencias cotidianas (traumáticas o perturbadoras). Es a través del paso de ser un receptor pasivo de las excitaciones externas e internas para venir a ser un agente activo que los niños utilizan estas plataformas gráficas para simbolizar y dramatizar sus conflictos. Así, tales conducirían a una reedición de la relación de los niños con sus objetos a través de la identificación proyectiva en el análisis.

En síntesis, los dibujos de los niños no sólo permitirían verificar las representaciones del nivel ideal y fantasmático de lo que está experimentando dentro de la familia y en sus relaciones interpersonales, sino que sus recuerdos evidenciarían la reconstrucción de sus vivencias, las cuales serían recontados para sí mismos - aspectos importantes en el proceso de reelaboración del duelo asociado a experiencias de separaciones parentales.

\section{La separación de los padres y el proceso de duelo:}

¿La experiencia de la separación de los padres está intrínsecamente asociada a la experiencia de la pérdida y el duelo - por lo tanto, implica un movimiento del recuerdo sostenido. Para la psicoanalista Killner:

"el duelo es un trabajo que uno hace cuando pierde un objeto amado y lo que tiene que hacer es retirar la carga del objeto, reinvertir en sí e invertir en otro objeto (...) pero, para eso, hay que se considerar que no hay un duelo completo, visto que hay siempre un resto, porque todo que se pierde no vuelve todo. (...) hay algo del Yo que se va (...) y ¿qué se hace con el resto que no se cierra nunca? Sublimar y matar el muerto" (nota de conferencia, 27 de junio de 2020). 
En el caso de la separación parental, uno tiende a no poder despedirse de la fantasía del otro y, así, vivir un duelo imposible, especialmente si esa experiencia no puede ser elabora debido a la emergencia de rememoraciones de huellas mnémicas vivenciales - por las cuales el retorno a la memoria de huellas mnémicas y/o vivenciales estimuladas por algo que haz emerger la experiencia de algo vivido o, en casos considerados traumáticos; o cuando el retorno se da por evocación repetitiva - donde la memoria emerge espontáneamente y tiene una cualidad presente, o sea, la persona vive y revive el fáctico asociado a la pérdida por la separación (Benyakar, 2020).

El primero en estudiar la experiencia de la pérdida de una figura de apego fue Sigmund Freud (1905, 1917 y 1926). Estrictamente, para Freud, el duelo no representaba un problema, pero propuso que la angustia psicológica causada por la pérdida estallaba debido a la ruptura de la dinámica entre el Yo y el objeto amado junto con sus respectivas representaciones narcisistas - en su mayoría, una parte del Yo se pierde con la ruptura. Según Freud, el duelo sería el resultado de una desinversión de la energía psíquica del objeto de amor para permitir una reinversión narcisista en el Yo (parcialmente vaciado). Este proceso intenta recuperar y emparejar las experiencias invertidas en el objeto amado en la conciencia. Finalmente, se produciría una identificación con el objeto perdido como un intento de compensar la ausencia de su objeto amado, y, así, superar la ausencia de imágenes que apoyaban su Yo Ideal. Una vez resuelto el duelo, el individuo desplazaría sus inversiones psíquicas en otro objeto. De lo contrario, la energía que debería ser dislocada se solidificaría en la imagen del objeto perdido, creando un ciclo rumoroso de recuerdos y fantasías nunca confirmadas, caracterizando un duelo patológico. 
Basado en eses presupuestos, Nasio (1997) enseñó que la experiencia del duelo se divide en tres movimientos psicodinámicos: en primer lugar, una evasión de la energía previamente invertida en el objeto amado (desinversión), luego la polarización de la energía (restante) en una sola imagen psíquica narcisista (para reinvertir en uno mismo) y, en tercer lugar, la inversión de esta catexis en otro objeto (o nueva representación del mismo). Es importante comprender que el objeto puede ser la representación de los padres como una combinación intacta, la representación de cada uno de los padres (antes unido al otro padre, ahora está separado), la dinámica familiar, el entorno que constituía este sistema (casa, escuelas, amigos, vecinos, etc.).

Para los niños, la separación de sus padres puede sentirse como un profundo daño narcísico, especialmente si persisten en su duelo a través de la introyección de los conflictos interparentales (Dolto, 1971, 1988). En este contexto, los niños pueden operar a través de la identificación proyectiva - principalmente la identificación con el agresor, como el que representan como el iniciador de la separación, o a través de la actuación, los comportamientos autoritarios o los comportamientos parentificados (los cuidadores de sus padres). Pero los registros de las huellas mnémicas se asocian, en estos casos, a múltiples inversiones que están dolientes y se procesarán en dinámicas diferenciadas.

El autor de este ensayo postula que, en esa coyuntura de pérdidas asociadas a múltiples inversiones, cuando la intensidad del duelo hacia un objeto invertido disminuye debido a su procesamiento (indicando que se liberó la energía psíquica para otras reinversiones en otro objeto), otro proceso de duelo se establece para procesar la pérdida de otro objeto, y así sucesivamente. Esto podría explicar por qué el proceso de psicoterapia 
para los niños de padres separados parece abordar múltiples frentes de conflicto entrelazadas y por qué resulta confuso para los padres cuando el niño presenta, con éxito, nuevas conductas adaptadas, pero retrocede (o incluso empeora) en otras esferas de la vida. Se supone que, hasta que se complete todo el procesamiento de estas frentes (que se completarán, pero en diferentes rutas y velocidades), los padres verían variaciones de las respuestas de los niños hasta que se llegue a una sincronización gradual de los procesos y una congruencia entre la experiencia del mundo interior del niño y su experiencia dentro de su entorno.

Otros factores contribuyen para la variabilidad de procesamiento. Por ejemplo, para los padres en situación de separación conflictiva, la posibilidad de que sus hijos "destruyan" lo que una vez fue la fuente de su confirmación narcísica (como padres) suena desalentadora. Esto también podría explicar su participación en diversos mecanismos de sabotaje del proceso de psicoterapia del niño. Estos sabotajes inconscientes restablecen el sistema familiar en roles que invitan a sus miembros a revivir (pasado) situaciones familiares (y alianzas), evocando estados personales familiares que recrean y refuerzan los patrones relacionales en la mente de los individuos - un proceso que Wachtel (1993) llamó psicodinámica cíclica y remite a un esfuerzo de evitación de la rememoración de vivencias dolorosas.

Las dinámicas pasadas y actuales de los padres suelen informar sobre la forma en que los niños responden a la separación y también ilustran esas dinámicas en sus dibujos. Dolto (1994) enseñó que una pareja que vive junta pero que es incapaz de amarse y aceptar los defectos del otro (y que sólo tiene la intención de guardar las apariencias) engendra un daño mucho más fuerte para el niño que aquellos que deciden separarse. Esto se debe a 
que el niño registra huellas mnémicas de la imagen de los padres adultos como modelos y representaciones de la forma de ser parte del mundo relacional (imagos). Las parejas que fingen amarse y aceptar los defectos del otro envían un mensaje inconsciente al niño que no le permite producir imagos completos, impulsándolo a identificarse con otros cuyas imágenes también están fragmentadas.

Para la mayoría de los psicoanalistas, es evidente que los niños señalan las psicopatologías de sus padres (Morgenstern, 1937; Klein, 1939; Dolto, 1984; para citar a algunos destacados psicoanalistas de niños). Como informa la literatura, esta premisa parece cierta - el niño quiere completar el proceso de duelo, pero algunos padres no están listos para seguir adelante, o, en otras palabras, listos para superar la castración generada por la separación. Parece menos doloroso para algunos padres volver a las estrategias anales de control y recrear un sistema que estanque el desarrollo emocional del niño para justificar su operación.

En correspondencia con la literatura revisada, la separación de los padres puede desencadenar impactos en la vida psíquica de los niños y en su capacidad para mantener la flexibilidad psicológica. Piedmont (2009) sugirió que el ejercicio de las funciones parentales simboligénicas funcionaría como un contenedor de emociones e impulsos en los niños. Por lo tanto, la separación puede crear un efecto disruptivo en el desarrollo del yo del niño, debido a que la función estabilizadora de los padres se vuelve ausente. En esta ausencia, los impulsos del niño se sobreexcitan y el yo del niño tratará de reprimirlos porque la sobreexcitación genera angustia. La formación de los síntomas sería el resultado del intento de contención de sus impulsos. De lo contrario, la eficiente relación paternal 
manejaría la saturación destructiva de las demandas del niño, a través del apoyo mutuo entre los padres.

Desde el punto de vista de los padres, la influencia de la situación de la separación en los niños también se refiere a la neurosis parental, como defiende Dolto (1994). Su tesis se centra en la premisa de que la cohesión del niño se configura a partir de una triangulación en la que el niño es uno de sus vértices con alguien que mantiene, según la dinámica dialéctica, la función paternante y maternante. Esto se debe a que el niño construyó una imagen que internalizó a estos adultos, la cual utilizará para representar su mundo relacional.

Schauder (2009) estuvo de acuerdo en que las dificultades asociadas a la separación ocultan las dificultades relacionadas con el complejo de Edipo de los padres. Estas dificultades se relacionan con representaciones inconscientes de la posibilidad de la privación de sus hijos. Dado que fueran el resultado de su deseo como emblema de su narcisismo, la pérdida del hijo (amor, identificación, residencia primaria, etc.) podía sentirse insoportable - especialmente si esta pérdida se significa como perderla para el otro padre, lo que probablemente influye en la forma de estructurar las castraciones simbólicas (Dolto, 1971, 1984). Dado que las castraciones simbólicas son interdicciones estructurantes y dependen de la inversión de los padres, su aplicación se vuelve problemática en ese contexto porque la mayoría de los padres separados (especialmente los que están todavía en situación de conflicto) invisten en la lesión narcisista de su rol parental en su identidad. El resultado podría ser que los niños interioricen que los límites y las fronteras se vuelven más débiles, prescindibles y se asocian con el abandono de las representaciones de sus padres. 
En la perspectiva de Darcourt (2009), estos síntomas equivaldrían a un desdoblamiento, para el niño, como una mutilación de su Yo. Tal división tiene un impacto en la dinámica del complejo de Edipo y en la estructuración de la triangulación con sus padres. Por ejemplo, durante un conflicto, el niño puede registrar huellas perceptivas y vivenciales que representan a uno de sus padres como un objeto destructivo (del otro padre) o si uno de los padres es representado como todopoderoso, el niño puede sentirse impulsado a atacar a este padre como solución para escapar de esta omnipotencia intrusa. Si uno de los padres es representado como un objeto humillado por el otro padre, el niño podría también sentir que necesita operar comportamientos para reparar al padre humillado - todas las posibilidades desestabilizan la triangulación, producen representaciones defectuosas de relaciones interpersonales sanas $\mathrm{y}$, en algunos casos, refuerzan al niño para identificarse con un padre devaluado.

Ambas perspectivas se reflejan en lo que Leprince (2010) propuso como padres viendo a sus hijos como la proyección de una continuidad narcisista de sí mismos. Como resultado, la separación cambia la dinámica conflictiva de la pareja según su resolución de Edipo. Si la pareja lo ha resuelto, el conflicto será la represión de la libido y la inversión en otro objeto. Por el contrario, los padres regresan, su conflicto se desplazará y engullirá al niño. Esta regresión de los padres sobre sus hijos engendraría una sumisión a la mala imagen de los padres por "la identificación con el agresor o el objeto atacado para mantener el vínculo inconsciente con los padres" (p.117). Esto se convertiría en una perversión ya que genera una identificación sádica y/o masoquista que también genera una lesión narcisista en el niño, corroborando la tesis de Dolto (1988). Para hacer frente a esta lesión, el niño actuará (activa o pasivamente, como evasión explícita de uno de los padres, o el intento de complacer a ambos, respectivamente) como una 
forma de expresión de su angustia. En algunos casos, especialmente cuando el niño es psicológicamente débil, respondería a sus padres con impulsos cuasi arcaicos como un último intento de mantener vivos a sus padres (como un intento de mantener la relación triangular pero distorsionada, como mencionan otros autores citados). La viñeta siguiente explora las representaciones de fantasías destructivas e identificatorias de un niño que bien ilustra tal dinámica:

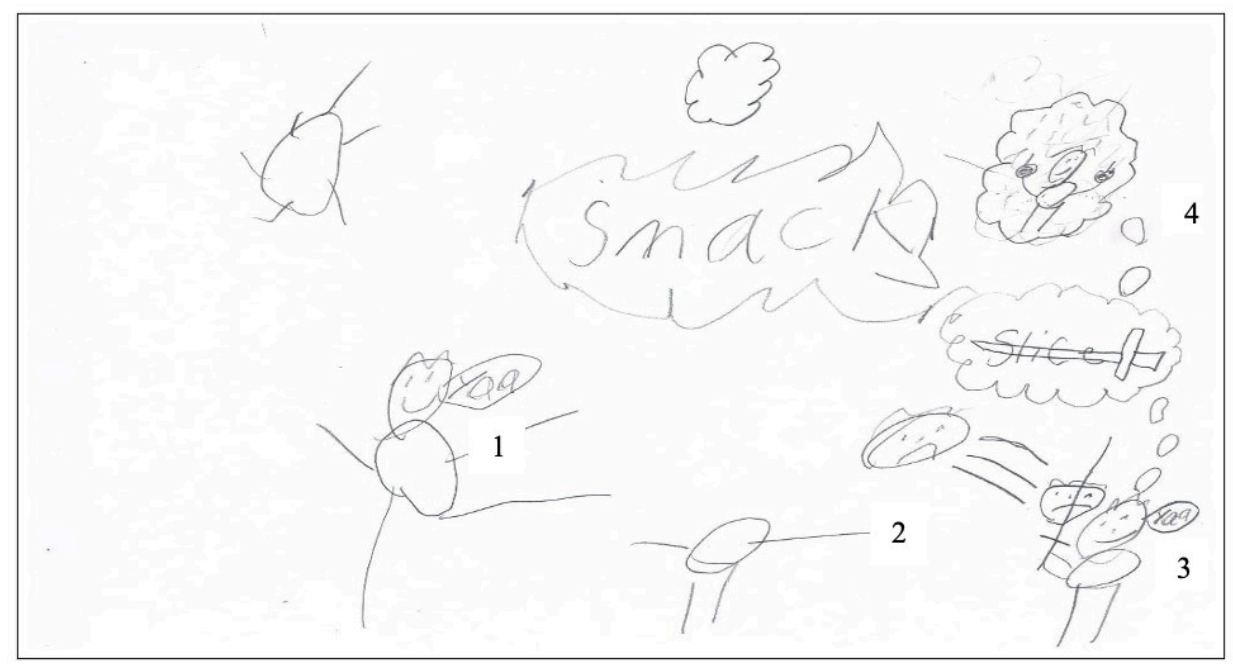

Un niño de seis años hizo este dibujo en su primera sesión. Describió una escena en la que, en un día soleado, su padre (1), pateó la cabeza de su madre (2). La cabeza de la madre fue golpeada (smack), atrapada por su espada y cortada (sliced), mientras él piensa “¡Yaa!” (3) para, al final, hacerlo victorioso, como está representado en sus pensamientos en el canto superior derecho (4) con sus puños hacia arriba. Aquí podemos ver la intensidad de los impulsos agresivos que configuran la alianza entre este niño y su padre. En efecto, se trata de una situación difícil y de alto conflicto, en la que el padre perpetró, en múltiples ocasiones, violencia 
física y verbal contra la madre delante del niño. En general, estas defensas tienen como objetivo mantener a los padres ocupados en un cierto nivel de interacción, como una fantasía en la que la triangulación estaría funcionando eficazmente.

No es raro escuchar que, para muchos padres separados, es fácil verse envueltos en una espiral de pérdidas y daños de sus imágenes narcisistas que resultan en una retroflexión de las inversiones emocionales en ellos mismos, disminuyendo la capacidad de producir insumos narcisistas hacia sus niños. Para Frisby y sus colaboradores (2012), en presencia de comorbilidades psicosociales como, por ejemplo, dificultades financieras, inestabilidad de la vivienda, vecindario violento, modalidades de relación abusiva, adulterio, trauma transgeneracional, los riesgos de una inversión insuficiente son aún mayores porque, como diría Zukerfelf (2016), la vivencia de vulnerabilidad es directamente relacionada a la gravedad de los factores disruptivos en el entorno y a la disminución de capacidades elaborativas necesarias para desarrollar potenciales de resiliencia.

\section{CONCLUSIONES}

El abordaje psicoanalítico y de otros los abordajes teóricos de la memoria más contemporáneas convergen en la premisa que esa es transformadora, dinámica, pero propensa a errores y distorsiones; y que el olvido tiene funciones de defensa o de adaptación que implica la relación intersubjetiva. Durante el periodo de latencia, tal premisa remite a un trabajo que articula la afluencia de varios mecanismos al fin sublimatorio asociado a las prohibiciones del superyó y a la operación de un proceso de desafectivización, que culminaría en la inserción del sujeto en la cultura escolar y, consecuentemente, a la sumisión a la agencia de lo sociocultural. Así que, en ese periodo, las proyecciones funcionarían como la realización 
de un deseo inconsciente desplazando el impulso libidinal de una representación simbólica a un contenido específico, que se condensa en una representación que se expresa por el sesgo de una acción de contenidos reprimidos.

Como el rememorar, el proyectivo también se organiza desde un sistema de significaciones y metáforas que les recrea y modifica en su red simbólica en la actualización de la transferencia. Se comprende, entonces, que, en ese contexto, la producción gráfica proyectiva facilitaría la simbolización de una trama conflictiva y la reelaboración de los recuerdos.

Evidentemente, existe la perspectiva de que, después de enfrentarse al proceso de cambio, la familia pueda o no implicar un duelo, que puede o no adaptarse. No obstante, es unánime entre los investigadores y teóricos que la separación de los padres en alto conflicto se configura como un factor estresante crónico porque generará cambios que conducirán a un desequilibrio psicosocial y afectarán a la capacidad de establecer relaciones parentales satisfactorias, caracterizándose como un fenómeno fáctico disruptivo de potencial traumático.

En el polo opuesto, por la vía de la elaboración, el funcionamiento de un proceso de duelo señalaría el intento inicial de superar los cambios provocados por la situación de separación, un proceso doloroso pero necesario para la cura. El procesamiento de este fenómeno fáctico se realizaría mediante la elaboración de huellas mnémicas perceptivas y vivenciales de acuerdo con las características y cualidades de la experiencia descrita por el sujeto involucrado. 
Esta revisión enseña que la experiencia de la separación de alto conflicto puede engendrar en la psique de los niños un efecto desestabilizador de las castraciones simbólicas en el contexto de la triangulación, que podría asociarse a una lesión narcísica, y podría engendrar la formación de representaciones no elaboradas, incluyendo una identificación con el sufrimiento de las figuras parentales y la posibilidad de interiorización de las representaciones de abandono de sus padres.

Este ensayo busco articular consideraciones teóricas sobre el uso de los recuerdos y los olvidos en la producción proyectiva gráfica de los niños latentes y la experiencia de la separación de sus padres. Deja en abierto, para futuras articulaciones e investigaciones, el tema de la culpa que se genera en los niños, ya que como bien se indicó, el superyó se instala como la introyección de las imagos parentales, lo que ampliaría la comprensión de los alcances de la posición subjetiva de los niños en una familia conflictiva.

\section{REFERENCIAS}

Aberastury, A. (1964). Teoría y técnica del psicoanálisis de niños. Paidós.

Anzieu, A. (2008). Le travail du dessin en psychothérapie de l'enfant. Dunod.

Benyakar, M. (2020). Mente, psique, el introducto y la memoria. Conferencia proferida en el Doctorado de Psicología. Universidad del Salvador. 30 de mayo de 2020.

Canteros, J. (2007). Memoria, sujeto, trauma. Revista de Psicoanálisis, 64(1), 93-124.

Darcourt, L. (2009). La clinique des enfants : la place du divorce. La lettre de l'enfance et de l'adolescence, 78(4), 19 - 23. doi:10.3917/ lett.078.0019. 
Dolto, F. (1948). Rapport sur l'interprétation psychanalytique des dessins au cours des traitements psychothérapiques. Psyché, 1, $324-346$.

Dolto, F. (1971). Psychanalyse et pédiatrie : les grandes notions de la psychanalyse : seize observations d'enfants. Éditions du Seuil.

Dolto, F. (1974). Les Cas Dominique. Éditions du Seuil.

Dolto, F. (1981). Au jeu du désir. Éditions du Seuil.

Dolto, F. (1984). L'image inconscient du corps. Éditions du Seuil.

Dolto, F. (1988). Quand les parents se séparent. Éditions du Seuil.

Dolto, F. (1994). Les chemins de l'éducation. Gallimard.

Freud, A. (1965). Normality and Pathology in Childhood: Assessments of Development. International Universities Press

Freud, A. (1971). The Psychoanalytical Treatment of Children (5th Ed.). Imago Publishing.

Freud, S. (1896). Carta 52. Obras Completas, tomo I. Amorrortu Editores.

Freud, S. (1900). La interpretación de los sueños. Obras Completas, tomos IV y V. Amorrortu Editores.

Freud, S. (1905). Tres ensayos de teoría sexual. Obras Completas, tomo VII. Amorrortu.

Freud, S. (1908). De la historia de una neurosis infantil (el Hombre de los Lobos). Obras Completas, tomo XVII. Amorrortu Editores.

Freud, S. (1911). Puntualizaciones psicoanalíticas sobre un caso de paranoia (Dementia Paranoides) descrito autobiográficamente. Obras Completas, tomo XII. Amorrortu Editores.

Freud, S. (1913). Tótem y Tabú. Algunas concordancias en la vida anímica de los salvajes y de los neuróticos. Obras Completas, tomo XIII. Amorrortu Editores. 
Freud, S. (1914). Recordar, repetir, elaborar. Obras Completas, tomo XII. Amorrortu Editores.

Freud, S. (1915). Conferencias de introducción al psicoanálisis. Obras Completas, tomo XV. Amorrortu Editores.

Freud, S. (1917). Duelo y melancolía. Obras Completas, tomo XIV. Amorrortu Editores

Freud, S. (1926). Inhibición, sintoma y angustia. Obras Completas, tomo XX. Amorrortu Editores.

Freud, S. (1937). Construcciones en el análisis. Obras completas, tomo XXIII. Amorrortu Editores.

Friedman, S. (1997). On the "true-false" memory syndrome: The problem of clinical evidence. American Journal of Psychotherapy, 51, 102-122.

Frisby, B.N., Booth-Butterfield, M., Dillow, M.R., Martin, M.M., \& Weber, K. D. (2012). Face and resilience in divorce. Journal of Social and Personal Relationships, 29, 715 - 735. doi: 10.1177/0265407512443452

Killner, A. (2020). El olvido, el recuerdo, la memoria y el duelo. Conferencia proferida en el Doctorado de Psicología. Universidad del Salvador. 27 de junio de 2020.

Klein, M. (1939). The Psycho-Analysis of Children. Hogarth Press.

Koss, M.P., Tromp, S. \& Tharan, M. (1995). Traumatic memories: Empirical foundations, forensic and clinical implications. Clinical Psychology Science and Practice, 2(2), 111-132.

Leprince, C. (2010). Le divorce : ses conséquences psychiques dans les liens familiaux. Le Divan Familial, 24(1), 109 - 122. doi:10.3917/ difa.024.0109.

Loftus, B. (1993). The reality of repressed memories. American Psychologist, 48(5), 518-537.

Morgenstern, S. (1927). Un cas de mutisme psychogène. Revue Française de Psychanalyse, 3, 492 - 504. 
Morgenstern, S. (1930). La psychanalyse infantile et son rôle dans l'hygiène mentale. Revue Française de Psychanalyse, 4, 136 - 162.

Morgenstern, S. (1937). Psychanalyse infantile : symbolisme et valeur clinique des créations imaginatives chez l'enfant. Denoël.

Morgenstern, S. (1939). Le symbolisme et le valeur psychanalytique des dessins infantiles. Revue Française de Psychanalyse, 9, 39 - 48.

Nasio, J-D. (1997). Le livre de l'amour et de la douleur. Presses Universitaires de France.

Piemont, L. (2009). The epigenesis of psychopathology in children of divorce. Modern Psychonalysis, 34, 98 - 116.

Sami-Ali, M. (2004). De la projection : Une étude psychanalytique. Dunod.

Schauder, C. (2009) Souffrances psychiques liées à la séparation conjugale, droit à l'enfant et postmodernité. La lettre de l'enfance et de l'adolescence, 78(4), 13 - 18. doi: 10.3917/lett.078.0013.

Siegel, D. (1995). Memory, trauma, and psychotherapy. Journal of Psychotherapy Practice and Research, 4, 93-122.

Tesone, J-E (2002). Conmemorar, recordar, olvidar, Revista de Psicoanálisis, $56,2$.

Van der Kolk, B., \& Van der Hart, O. (1991). The historical truth of psychoanalytic reconstructions. International Review of Psychoanalysis, 12, 187-197.

Vinay, A. (2007). Le dessin dans l'examen psychologique de l'enfant et de l'adolescent. Dunod.

Von Helmuth, H. (1919). A Study of the Mental Life of the Child. Nervous and Mental Disease Publishing Company.

Wachtel, P.L. (1993). Cyclical psychodynamics I: vicious cycles (pp. $16-$ 67). In: P.L. Wachtel (1993). Therapeutic communication: Principles and effective practice. Guilford Press. 
Zukerfeld, R. (2016). Procesos Terciarios: de la vulnerabilidad a la resiliencia. Lugar.

Envío a dictamen: 16 de abril de 2021

Reenvío: 2 de junio de 2021

Aprobación: 18 de junio de 2021

Dilcio Dantas Guedes. Candidato de Doctorado en Psicología (Universidad del Salvador). Miembro del Grupo de Investigación "Psicoanálisis y/o lo disruptivo" (Universidad del Salvador/Asociación Psicoanalítica Argentina, Buenos Aires). Psicoterapeuta en Family Services Toronto. Correo electrónico: dilcio@gmail.com 